\title{
The use of dithiothreitol for the quantitative analysis of elemental sulfur concentrations and isotopes in environmental samples
}

\author{
Martin R. Kurek ${ }^{1}$, William P. Gilhooly III ${ }^{1 *}$, Gregory K. Druschel ${ }^{1}$, Molly D. O’Beirne ${ }^{2}$, Josef P. \\ Werne $^{2}$
}

${ }^{1}$ Department of Earth Sciences, IUPUI, Indianapolis, IN, USA; markurek@ umail.iu.edu, wgilhool@iupui.edu,gdrusche@iupui.edu

${ }^{2}$ Department of Geology and Environmental Science, University of Pittsburgh, Pittsburgh, PA, USA; mdobeirne@pitt.edu, jwerne@pitt.edu *corresponding author: wgilhool@iupui.edu

This is the author's manuscript of the article published in final edited form as:

Kurek, M. R., Gilhooly III, W. P., Druschel, G. K., O’Beirne, M. D., \& Werne, J. P. (2018). The use of dithiothreitol for the quantitative analysis of elemental sulfur concentrations and isotopes in environmental samples. Chemical Geology. https://doi.org/10.1016/j.chemgeo.2018.01.014 


\begin{abstract}
Determining the concentration and isotopic composition of elemental sulfur in modern and ancient environments is essential to improved interpretation of the mechanisms and pathways of sulfur utilization in biogeochemical cycles. Elemental sulfur can be extracted from sediment or water samples and quantified by converting to hydrogen sulfide. Alternatively, elemental sulfur concentrations can themselves be analyzed using HPLC and other methodologies; however, the preparation and analysis times can be long and these methods are not amenable to stable isotopic analysis. Current reduction methods involve the use of costly and specialized glassware in addition to toxins such as chromium chloride or cyanide to reduce the sulfur to hydrogen sulfide. The novel reduction method presented here uses dithiothreitol (DTT) as a less toxic reducing agent to obtain both elemental sulfur concentrations and isotopic composition from the same sample. The sample is dissolved in an aqueous or organic liquid medium and upon reaction with DTT, the elemental sulfur is volatilized as hydrogen sulfide and collected in a sulfide trap using an inexpensive gas extraction apparatus. The evolved sulfide concentrations can easily be measured for concentration, by absorbance spectrophotometery or voltammetry techniques, and then analyzed for sulfur isotopic composition. The procedure is quantitative at $>93 \%$ recovery to dissolved elemental sulfur with no observed sulfur isotope fractionation during reduction and recovery. Controlled experiments also demonstrate that DTT is not reactive to sulfate, sulfite, pyrite, or organic sulfur.
\end{abstract}

Keywords: elemental sulfur, dithiothreitol, DTT, sulfur isotopes, cryptic cycles 


\section{Introduction}

The biogeochemical transformation of sulfur in sediments is a critical microbial pathway in marine and lacustrine sediments. Microbial sulfate reduction is responsible for a significant portion of organic matter oxidation in marine sediments (Jørgensen 1982). In marine systems, up to $90 \%$ of the hydrogen sulfide produced can be reoxidized to sulfur intermediate compounds and eventually to sulfate by oxidation with molecular oxygen, iron(III), nitrate, or other oxidants via multiple oxidation pathways (Jørgensen, 1982; Zopfi et al., 2004; Picard et al., 2016). In addition to other key sulfur intermediates such as polysulfides $\left(\mathrm{S}_{\mathrm{n}}{ }^{2-}\right)$, thiosulfate $\left(\mathrm{S}_{2} \mathrm{O}_{3}{ }^{2-}\right)$, and sulfite $\left(\mathrm{SO}_{3}{ }^{2-}\right)$, elemental sulfur is a significant sulfur intermediate often observed in modern systems. Elemental sulfur, itself, may be oxidized, disproportionated, or reduced (a)biotically, and is also an important part of pyritization pathways (Thamdrup et al., 1994a; Rickard et al., 2017). The near-quantitative reduction of sulfate to sulfide followed by reoxidation through elemental sulfur is rapid and difficult to observe directly or quantify such that these reactions can be said to be cryptic (Canfield et al., 2010; Hansel et al., 2015). Although the overall isotopic fractionation for biotic and abiotic sulfide oxidation is minimal $( \pm 5 \%)$ (Fry et al., 1988; Zerkle et al., 2009; Brabec et al., 2012), little is known about fractionation associated with key intermediate steps such as those involving elemental sulfur (Johnston et al., 2014).

Elemental sulfur exists in a variety of physicochemical forms, varying in structure, size, and surface character. Although many studies refer to this intermediate as 'zero valent sulfur' (or 
$\mathrm{S}^{0}$ ), elemental sulfur is a pure element that is naturally unstable as a single atom (Steudel, 1988), and present most commonly as $\mathrm{S}_{8}$ rings. The bond lengths between individual sulfur atoms within the sulfur-ring vary depending on temperature and pressure, resulting in different chemical and physical properties (Steudel \& Eckert, 2003). Of these configurations, $\alpha-S_{8}$ is the most thermodynamically stable and the least reactive allotrope (Steudel, 1989). Other allotropes of elemental sulfur will convert to $\alpha-\mathrm{S}_{8}$ at normal earth surface temperatures $\left(\sim 25^{\circ} \mathrm{C}\right.$ to $\left.50^{\circ} \mathrm{C}\right)$, therefore, most of the elemental sulfur preserved in geologic and environmental samples is found as $\alpha-\mathrm{S}_{8}$ (Steudel \& Holdt, 1989).

Microorganisms also produce elemental sulfur as a function of metabolic transformations (Dahl \& Prange, 2006); such biologically-produced sulfur is fundamentally different in some properties from $\alpha-S_{8}$ (Kleinjan et al., 2003) but similar to $\alpha-S_{8}$ in terms of bulk structure (George et al., 2008). Biologically-produced sulfur is typically of lower density than $\alpha-S_{8}$, and has a different surface property such that it does not partition into hexadecane solvent (Kleinjan, 2005). Sulfur sols, colloidal suspensions of elemental sulfur or sulfur-rich compounds, may serve as an analogue for biologically-produced elemental sulfur or neoformed nanoparticulate elemental sulfur. Different preparations of sulfur sols can vary in surface character (hydrophobic or hydrophilic) based on incorporation of chain-like sulfur compounds or association with functionalized organic groups (Steudel, 2003). Weimarn Sols (hydrophobic character) and Raffo sols (hydrophilic character) are nanoparticulate to colloidal (for details and additional references see Steudel, 2003), and grow through a combination of rapid aggregation and slower Ostwald 
ripening (Garcia \& Druschel, 2014).

A number of methods have been used to extract elemental sulfur from geologic and environmental samples. The overall procedures typically require a solvent to separate the elemental sulfur from the sample, followed by a reduction procedure to convert the extracted elemental sulfur into hydrogen sulfide for quantification. The use of a chromium(II) complex to reduce elemental sulfur and pyrite is a widely adopted method for obtaining concentrations, sulfur isotope data, and sulfate reduction rate measurements (Canfield 1986; Fossing et al., 1989; Newton et al., 1995; Kallmeyer et al., 2004; Burton et al., 2008; Muller et al., 2017). Although this effective method can be used to reduce separate organic extracts of elemental sulfur, the procedure generates large volumes of chromium(III) waste. Cyanide extraction of elemental sulfur is highly specific and efficient (Kamyshny, 2009); however, the method is hazardous and requires considerable expertise. Elemental sulfur can also be extracted from organic compounds, sediments, or waters with acetone and trapped on copper wire (Hardman, 1935); however, such methods are non-quantitative and have low extraction efficiency.

Dithiothreitol (DTT) is an alternative reductant that can be added to molecules containing thiol groups to either prevent oxidation or to reduce disulfide bonds (Cleland, 1964). Originally used for the study of enzyme kinetics, this reductant was recently adopted for quantifying the relatively high concentrations of elemental sulfur found in industrial and agricultural samples such as drywall and wine (Kwasniewski et al., 2011). Presented here is a robust modification of 
the DTT method to reduce elemental sulfur extracted from geologic and environmental samples (5-100 $\mu \mathrm{M})$ in both the laboratory and field setting. The procedure was further adapted for sulfur isotopic analysis of the elemental sulfur reduced by DTT.

\section{Materials and procedures}

\subsection{Dithiothreitol preparation}

The DTT (Fisher, BP172) stock powder was stored in a $-20^{\circ} \mathrm{C}$ freezer. Approximately $1 \mathrm{~L}$ of 18 $\mathrm{M} \Omega$ deionized water was bubbled with nitrogen gas for 5 minutes to degas oxygen. DTT $\left[\mathrm{HSCH}_{2} \mathrm{CH}(\mathrm{OH}) \mathrm{CH}(\mathrm{OH}) \mathrm{CH}_{2} \mathrm{SH}\right]$ was made to a final concentration of $20 \mathrm{mM}$ in $10 \mathrm{~mL}$ of oxygen-free water. Degassed water is important for the preparation of DTT solution because the thiol groups on the molecule rapidly oxidize in the presence of molecular oxygen to form a disulfide bond. Because of this reactivity to oxygen, the half-life of DTT at $\mathrm{pH} 8.5\left(0^{\circ} \mathrm{C}\right)$ is 11 hours (Stevens et al., 1983). To prevent oxidation, the prepared DTT solution was stored below $0^{\circ} \mathrm{C}$. DTT concentrations were scaled to be at least 8 -fold excess of the working range of elemental sulfur concentrations (5 to $100 \mu \mathrm{M}$ ). Based on repeated use of this reductant, optimal results were obtained with DTT solutions no older than 7 days.

\subsection{Standard procedure for DTT reduction}


The reduction procedure consists of two steps: (1) DTT reduction under basic conditions followed by (2) acidification to collect the reduced product (Figure 1). All reactions were conducted in $10 \mathrm{~mL}$ vacutainers (BD, 8282465). Vacutainers were ideal for this method because they are gas-tight, are easily transported and stored, allow analysis of small sample sizes, and simple to set up. Gas-inlet and outlet tubing were connected using luer-lock fittings to the vacutainer and the outflow was plumbed to a sulfide trap containing $8 \mathrm{~mL} 0.1 \mathrm{M}$ ammonium hydroxide. All reagents were made in $18 \mathrm{M} \Omega$ deionized water. Prior to reduction, all samples are mixed with ethanol or methanol to put elemental sulfur in solution. Sections 2.5 and 2.6 describe the method for dissolving elemental sulfur from solid phase samples.

First, to reduce elemental sulfur in solution, sodium citrate (17 mM; Fisher Scientific, S25545) was added in excess to a sufficient volume of elemental sulfur dissolved in organic or aqueous solution in a glass vacutainer to a final volume of $8 \mathrm{~mL}$ (Figure 1a). The final $\mathrm{pH}$ of the solution was adjusted to 11 by dropwise addition of sodium hydroxide solution (1 M; Fisher Scientific, S320-500). Both the reagents have a shelf life of at least 6 months. The vacutainer was sealed after adding the sample and citrate solution. The remaining $2 \mathrm{~mL}$ of headspace in the vacutainer was required to exsolve the hydrogen sulfide gas produced during the acidification step (see below). After purging the apparatus for 5 minutes with nitrogen gas, the reducing agent was injected with a gas-tight syringe into the reaction vacutainer to a final concentration of $500 \mu \mathrm{M}$ DTT. The extraction apparatus was continuously bubbled with nitrogen gas (3-5 bubbles per second) and heated at $50^{\circ} \mathrm{C}$ on a 36-position block heater for 45 minutes to quantitatively reduce 
elemental sulfur to non-volatile bisulfide. Bisulfide is an ion, which will remain dissolved in the reaction vessel until protonation with acid.

The second step acidifies the sample mixture to protonate the bisulfide and transfers the sample hydrogen sulfide gas into a sulfide trap (Figure $1 \mathrm{~b})$. Concentrated phosphoric acid $(0.5 \mathrm{~mL})$ was then injected into the reaction vacutainer to protonate the bisulfide to hydrogen sulfide gas that is transferred to the sulfide trap by the nitrogen carrier gas. Under high $\mathrm{pH}$ conditions of the trap solution, the hydrogen sulfide is deprotonated to non-volatile bisulfide. Concentrated phosphoric acid (100-105\%), prepared according to Coplen et al. (1983), was used for the experiments reported here; however, $85 \%$ phosphoric acid would achieve the same results. Due to the small headspace within the extraction vessels, a strong acid (e.g., 85-105\% phosphoric acid) was preferable for the acidification because only a small volume was necessary to substantially lower the $\mathrm{pH}$. Furthermore, phosphoric acid has a high boiling point compared to more volatile acids such as hydrochloric or nitric, and therefore will not transfer in the vapor phase to the collection traps. After 90 minutes of acidification, the trap vacutainer was removed from the extraction apparatus. The sulfide trap was inverted several times to ensure complete mixing, an aliquot of approximately $3 \mathrm{~mL}$ was pipetted for sulfide quantification by spectrophotometry (Section 2.3) or voltammetry. The remaining sulfide in solution was prepared for stable sulfur isotope analysis (Section 2.4).

\subsection{Concentration measurements}


Sulfide concentrations were routinely measured using colorimetry. For this method, $3 \mathrm{~mL}$ of sulfide trap solution was combined with $0.3 \mathrm{~mL}$ each of two colorimetric reagents (methylene blue, Hach reagents 181632 and 181732) in a clear-sided $4 \mathrm{~mL}$ disposable cuvette. The cuvette was then inverted to mix and allowed to sit for 5 minutes to ensure a complete reaction. The cuvette was then placed in a portable spectrophotometer (Hach, DR2800 Portable Spectrophotometer) and the absorbance of the sample was measured at $665 \mathrm{~nm}$. The sample concentration was calculated using an external calibration curve made with dilutions from a stock sodium sulfide solution (Fisher Scientific, S425-500) ranging from 5 to $150 \mu \mathrm{M}$ sulfide. For a subset of samples, concentrations were also measured using a benchtop microplate reader (Biotek Epoch 2) in $300 \mu \mathrm{L}$ plastic 96-well plates.

Sulfide concentrations were also determined on a subset of samples using voltammetry. The sample from the sulfide trap was diluted (1:5) and the sulfide concentration was measured using cyclic voltammetry on a hanging mercury drop electrode (Model 303A SMDE, Princeton Applied Research) and a potentiostat (Model DLK-70, Analytical Instrument Systems, Inc.). The measurements were performed with an $\mathrm{Ag} / \mathrm{AgCl}$ reference electrode and a platinum wire counter electrode. Scan rate parameters for cyclic voltammetry were $1 \mathrm{~V} / \mathrm{s}$ over the potential range -0.1 $\mathrm{V}$ to $-1.8 \mathrm{~V}$ with a 2 second deposition time. Sulfide was quantified with an external calibration curve made with dilutions from a stock sodium sulfide solution (5 to $20 \mu \mathrm{M}$ sulfide). The calibration curve was made from peaks at $-0.8 \mathrm{~V}$ on the voltammograms, where the sulfide was 
stripped off the mercury working electrode surface (Luther et al., 2008).

\subsection{Sample preparation for isotopic analysis}

After sulfide concentrations were measured, the remaining sample was converted to silver sulfide $\left(\mathrm{Ag}_{2} \mathrm{~S}\right)$ by addition of $1 \mathrm{~mL}$ of $3 \%$ silver nitrate (Fisher Chemical, S486-100) in 10\% ammonium hydroxide (Fisher Scientific, A669-212). The mixture was stored in the dark for 24 hours to allow complete conversion to silver sulfide. The sample was recovered from solution by vacuum filtration through a $0.2 \mu \mathrm{m}$ polycarbonate filter (Whatman, 7008703 ) and the precipitate was dried at $50^{\circ} \mathrm{C}$ for 24 hours. Silver sulfide precipitates were scraped from the filters and homogenized to a fine powder using an agate mortar and pestle.

Silver sulfides were weighed in the amount of $0.2 \mathrm{mg}$ into tin capsules $(3 \times 5 \mathrm{~mm})$ for sulfur isotopic analysis. The samples were combusted to sulfur dioxide gas in an elemental analyzer (Thermo, EAIsolink) coupled under continuous flow to a stable isotope ratio mass spectrometer (Thermo, DeltaV Plus). Sulfur isotope values $\left(\delta^{34} \mathrm{~S}\right)$ were reported relative to Vienna Canyon Diablo Troilite (VCDT) by normalization to three international reference materials (IAEA S1 = $0.3 \%$; IAEA S2 $=22.62 \%$; IAEA S3 $=-32.49 \%$ ). Linear regression bracketed the full isotopic range of the samples and corrected for scale compression. All $\delta^{34} \mathrm{~S}$ values were calculated according to standard notation in per mil (\%) deviations from VCDT, where $\delta^{34} \mathrm{~S}=$ $\left[\left({ }^{34} \mathrm{~S} /{ }^{32} \mathrm{~S}_{\text {sample }}\right) /\left({ }^{34} \mathrm{~S} /{ }^{32} \mathrm{~S}_{\mathrm{VCDT}}\right)-1\right] \times 1000$. The analytical precision was $0.2 \%$ or better. Isotope 
fractionation between the reactant and product of a reaction was calculated by difference, where

$\Delta^{34} \mathrm{~S}=\delta^{34} \mathrm{~S}_{\text {starting material }}-\delta^{34} \mathrm{~S}_{\text {reduced }}$

\subsection{Reduction of sulfur species}

DTT reduction efficiency was tested on an elemental sulfur solution with known concentration (from stock solutions of $1.84 \mathrm{mM}$ elemental sulfur in methanol and 4.98 elemental sulfur in ethanol; Fisher Scientific, S595-500). The same elemental sulfur powder was suspended in water (wetted) and also tested for recovery. Colloidal sulfur was measured in the forms of Weimarn and Raffo sols after Steudel, (2003) to mimic nanoparticles commonly found in the natural environment. Weimarn sols were made by a 1:6 dilution of sulfur-saturated methanol into water containing $0.1 \mathrm{M} \mathrm{KCl}$, and Raffo sols were made by acidifying sodium thiosulfate in $0.1 \mathrm{M} \mathrm{KCl}$. The percent recovery of elemental sulfur from Weimarn sols was determined based on the amount of elemental sulfur powder added to form the sol. Raffo sol synthesis produces several sulfur compounds in addition to elemental sulfur, therefore, the recovery of elemental sulfur from Raffo sols was based on the theoretical amount of elemental sulfur in the sol formed from the acidification of thiosulfate. A variety of organic and inorganic sulfur compounds (sodium sulfate anhydrous, sodium sulfite anhydrous, sodium thiosulfate, sodium tetrasulfide, L-cysteine, Suwannee River organic matter, crystalline pyrite and shale) were also tested for recovery by DTT reduction (Section 2.2). 


\subsection{Procedure for extracting elemental sulfur in sediments}

The extraction procedure was tested on lake sediments from Little Sandy Lake, Minnesota. Little Sandy Lake is an oxic lake with reducing sediments that contain free dissolved sulfide in the pore waters (Mayer \& Myrbo, 2013). The lake sediments were stored frozen upon collection. Frozen sediments were thawed for 24 hours and $\sim 0.5 \mathrm{~g}$ of the sample was added to a glass vial with $10 \mathrm{~mL}$ of HPLC grade methanol (Fisher Chemical, A452-4). The methanol-sample mixture was agitated on a roller for 3 days to quantitatively extract the elemental sulfur from the sample. The solution was then filtered through a $0.2 \mu \mathrm{m}$ syringe filter (Thermo Scientific, 00210899) to remove particulates. The solution was stored in a glass vial until analysis. The procedure was also tested on Pennsylvanian age ( 320 million years old) pyritic shale as a negative control. Initial analyses indicate (Sections 3.2.4 and 3.2.5) that the sulfur in the shale contains both pyrite and organic sulfur.

\section{Results}

\subsection{Optimal $\mathrm{pH}$ and reaction time}

Kwasniewski et al., (2011) recommended 20 mM DTT for extracting elemental sulfur concentrations in industrial samples (e.g. petroleum, building materials, food and alcohol). In their procedure, DTT was used to recover elemental sulfur that was externally spiked into large 
sample matrices but native elemental sulfur concentrations were not measured directly from their samples (Kwasniewski et al., 2011). The method was modified here to use DTT concentrations at great excess to elemental sulfur concentrations reported for marine and lacustrine environments (<1 to $555 \mu \mathrm{M})$ (e.g., Zopfi et al., 2004).

Kwasniewski et al., (2011) observed complete and quantitative elemental sulfur reduction at a $\mathrm{pH}$ of $11(109 \% \pm 9)$. A single-step reduction/volatilization method buffered to a $\mathrm{pH}$ of 6 gave recoveries of at least $80 \%$ (Kwasniewski et al., 2011); however, the application of this method to stable isotopic analysis requires complete recovery. To confirm the ideal $\mathrm{pH}$ range, different volumes of $1 \mathrm{M} \mathrm{NaOH}$ were added to vary the $\mathrm{pH}$ from 11 to 14 in $62.5 \mu \mathrm{M}$ elemental sulfurmethanol solutions, while maintaining a DTT concentration of $0.5 \mathrm{mM}$ in order to determine the ideal extraction $\mathrm{pH}$. Based on these experiments, recovery was maximized at $\mathrm{pH} 11$ (Figure 2).

Prepared solutions of $31.3 \mu \mathrm{M}$ and $62.5 \mu \mathrm{M}$ elemental sulfur in HPLC grade methanol were reduced with DTT and the sulfide absorbance was measured over a one hour period to determine the optimal reaction time (Figure 3). Absorbance stabilized within 45 minutes for both concentrations, indicating that elemental sulfur is quantitatively recovered after 45 minutes of reaction time (Figure 3). Both concentration curves (Figure 3) exhibit 2 areas of rapid absorbance increase with respect to time which could be indicative of a two-step reaction or from matrix interferences with the Hach colorimetric solutions. 
The amount of time between the completion of the reaction and when the absorbance measurements were made was also studied. The reaction is complete after 45 minutes; however, hydrogen sulfide concentrations should be measured immediately after completion to avoid analytical artifacts of the excess reactant. For prepared solutions of $62.5 \mu \mathrm{M}$ elemental sulfur in methanol 1 hour after DTT reduction, the absorbance increased by about 0.042 absorbance units (an $8.8 \%$ increase) over the course of 4 hours. In addition to these relatively small increases, the absorbance of the reaction mixtures changed over the course of 4 days. Prepared solutions of 62.5 $\mu \mathrm{M}$ elemental sulfur in HPLC grade methanol were reduced for 45 minutes. The reaction mixtures were sealed and left undisturbed for 4 days to study how the produced sulfide interacts with the reaction matrix. A steady decrease of 0.214 absorbance units (a $45.0 \%$ decrease) was observed from 24 hours after the reaction concluded to the end of the 4 day period.

\subsection{Reduction efficiency and specificity}

A suite of sulfur containing compounds, discussed in the following sections, were reacted with

DTT to determine whether the reaction is quantitative and specific to reduced sulfur species (Table 1). DTT reducible sulfur included dissolved, wetted and colloidal elemental sulfur as well as polysulfide and thiosulfate. Non-reducible sulfur included sulfate, sulfite, pyrite, and organic sulfur. The sulfide produced from DTT reduction was quantified using absorption spectroscopy and cyclic voltammetry. Recoveries for three separate methods for measuring sulfide concentrations were quantitative within the error of the detection. Sulfide concentrations 
measured by absorption spectroscopy could be detected at 1 to $5 \mu \mathrm{M}$ and accurately quantified within the range of 5 to $100 \mu \mathrm{M}$. Cyclic voltammetry has a lower limit of quantification at $1 \mu \mathrm{M}$.

\subsubsection{Dissolved and wetted elemental sulfur}

DTT reduction was tested on a solution containing 57.5 $\mu \mathrm{M} \alpha-\mathrm{S}_{8}$ dissolved in HPLC grade methanol and $62.3 \mu \mathrm{M} \alpha-\mathrm{S}_{8}$ dissolved in reagent grade ethanol. This stock solution of elemental sulfur is representative of concentrations observed in the natural environment (Zopfi et al., 2004). Solutions made with ethanol were preferable because elemental sulfur is more soluble in ethanol than methanol (Alberta Environment and Parks, 2015; Steudel 2015).

Elemental sulfur recoveries were above $93 \%$ according to all analysis methods. Using the portable spectrophotometer, the elemental sulfur was recovered from methanol with a $99.2 \% \pm$ 5.4 yield and from ethanol with a $93.4 \% \pm 4.2$ yield (Table 1$)$. With the microplate reader, elemental sulfur was recovered from methanol with a $94.5 \% \pm 4.2$ yield and a $97.0 \% \pm 3.4$ yield from ethanol. Using cyclic voltammetry, the elemental sulfur was recovered with a $102 \% \pm 0.4$ yield from methanol and a $105 \% \pm 1.0$ yield from ethanol. Elemental sulfur powder suspended in water (wetted) in concentrations ranging from $26-90 \mu \mathrm{M}$ was reducible and resulted in partial elemental sulfur recovery with a $45.4 \% \pm 14.4$ yield determined using the portable spectrophotometer. 


\subsubsection{Colloidal elemental sulfur and polysulfides}

To replicate the suspended particle fraction of elemental sulfur that may be found in the natural environment, the reduction procedure was performed on samples of sulfur in the form of both a Weimarn sol and a Raffo sol. The reduction was performed on a $62.5 \mu \mathrm{M}$ solution of the Weimarn sol and $125 \mu \mathrm{M}$ solution of the Raffo sol; both concentrations were within the range observed for elemental sulfur in aquatic environments (Zopfi et al., 2004). The elemental sulfur was recovered with a $<10 \%$ yield as measured by the portable spectrophotometer for both sols (Table 1). Polysulfides are also important components of marine and lacustrine sulfur cycles. To represent polysulfides, the reduction procedure was tested on a $143 \mu \mathrm{M}$ solution of sodium tetrasulfide and yielded a complete recovery of $100 \% \pm 2.3$ (Table 1).

\subsubsection{Sulfate, sulfite and thiosulfate}

The DTT reduction procedure did not extract sulfate or sulfite from solution. In separate trials, various concentrations of sodium sulfate $(25,50,75$, and $100 \mu \mathrm{M})$ were reacted with DTT according to the method presented above. In all trials, the trap solution did not produce an absorbance signal that was different from the blank. The same outcome was observed in experiments with higher concentrations of sulfate representative of brackish water, normal seawater and brines. Concentrations of 1,100 , and $500 \mathrm{mM}$ sodium sulfate were not reduced to sulfide. (Table 1). Likewise, triplicate reactions of sodium sulfite $(100 \mu \mathrm{M})$ indicated that sulfite 
was not reducible by DTT. Selectivity was also tested on thiosulfate. A solution of $63.4 \mu \mathrm{M}$ sodium thiosulfate was reacted with DTT and resulted in a $24.9 \% \pm 6.2$ recovery of elemental sulfur (Table 1).

\subsubsection{Pyrite}

The reduction procedure was tested on a $200 \mu \mathrm{M}$ pyrite-sulfur (pyrite mineralogy was confirmed by X-ray diffraction) suspension in water to determine whether solid phase inorganic pyritesulfur reacts with DTT. The resulting absorbances were below the detection limit of the colorimetric method (Table 1).

The reduction procedure was also performed on a sample of 320 million year old pyritic marine sediments (Pennsylvanian aged shale). The sample represents a compositionally complex mixture of pyrite and organic sulfur (see 3.2.5) preserved in siliciclastic sediment. The concentration of pyrite-sulfur (1830 $\mu \mathrm{g}$ S/g sediment) was determined with the chromium reduction method (Canfield et al., 1986). Six separate $0.5 \mathrm{~g}$ splits of dried homogenized sediment were extracted with methanol (see Section 2.6) and reacted with DTT. All absorbances of the trap solution were below the detection limits of the calibration curves. When the amount of methanol-extracted sample was increased from $200 \mu \mathrm{L}$ to $1 \mathrm{~mL}$, the absorbances still did not change. The amount of DTT added was also increased from $200 \mu \mathrm{L}$ to $1 \mathrm{~mL}$ and the resulting absorbances were still below detection, indicating the sample did not contain methanol 
extractable sulfur (Table 1).

\subsubsection{Organic sulfur}

A sulfur-containing amino acid, a natural sample of dissolved organic matter, and an organic-rich shale were used to determine whether DTT reduces organic sulfur molecules (Table 1). A $152 \mu \mathrm{M}$ solution of L-cysteine reacted with DTT did not produce an absorbance signal different from the blank using the portable spectrophotometer. To test recently formed organic matter, a suspended solution of $0.831 \mathrm{mg} / \mathrm{mL}$ Suwannee River organic matter containing $0.464 \%$ S (Perdue, 2013) was tested for reduction by DTT. Natural organic matter from this river in Southeastern Georgia has been used as standard and reference material by the International Humic Substance Society since 1982 (Perdue, 2013) and serves as a representative material of sulfur-containing organic matter found in aquatic systems. The reactions did not produce a detectable sulfide signal with the portable spectrophotometer. The final test included DTT reductions of a pyritic black shale methanol extract. The organic sulfur concentration $(118 \mu \mathrm{g}$ $\mathrm{S} / \mathrm{g}$ of sediment) of the shale was determined by combusting the non-reactive residue produced during pyrite extraction (according to Canfield et al., 1986) in the EAIsoLink. Sulfide reduced from organic sulfur was not recovered in three separate DTT reactions.

\subsubsection{Elemental sulfur in recent sediments}


In addition to testing ancient sediment and dissolved organic matter, elemental sulfur from lake sediments was reduced by DTT. Elemental sulfur was recovered from the sediment samples and the average concentrations ( $\mu$ g elemental sulfur/g sediment) were plotted in a depth profile (Figure 4). The highest elemental sulfur concentrations were observed within the upper $5 \mathrm{~cm}$ of the sediments. Elemental concentrations decreased with depth in the lake sediments.

\subsection{Sulfur isotopes}

Replicate solutions ( $\mathrm{n}=3$ ) of materials observed to be DTT-reducible (Table 1) including dissolved elemental sulfur in ethanol, water (wetted), thiosulfate, and tetrasulfide were analyzed for possible sulfur isotope fractionation during reduction. The sulfide produced was precipitated as silver sulfide and analyzed for sulfur isotopes (Figure 5). The bulk sulfur in the DTT had an average $\delta^{34} S$ value of $-8.1 \% \pm 0.1$. Solid elemental sulfur powder had an average $\delta^{34} S$ value of $20.3 \%$ \pm 0.6 . Sulfide produced during DTT reduction of elemental sulfur powder dissolved in ethanol or wetted had respective $\delta^{34} \mathrm{~S}$ values of $19.7 \%_{0} \pm 0.4$ and $20.6 \%$ o \pm 0.4 . Compared to the isotopic composition of the starting material, there is no isotopic fractionation observed during the DTT reduction of dissolved or wetted elemental sulfur $\left(\Delta^{34} \mathrm{~S} \approx 0 \%\right.$ o $)$. Sodium tetrasulfide had an average $\delta^{34} \mathrm{~S}$ of $19.1 \% \pm 0.3$, while the $\delta^{34} \mathrm{~S}$ of DTT-reduced tetrasulfide had a lower $\delta^{34} \mathrm{~S}$ value of $14.8 \%$ o \pm 0.05 . Sodium thiosulfate had an average $\delta^{34} \mathrm{~S}$ of $-8.1 \% \pm \pm 0.02$, and elemental sulfur resulting from the acidification step during reduction of thiosulfate had an average $\delta^{34} \mathrm{~S}$ of $-18.4 \%$ o \pm 0.9 . The identical sulfur isotope composition of the DTT thiols and the thiosulfate was 
purely coincidental.

\section{Discussion}

The DTT reduction method was optimized for quantitative abundance and isotopic analysis of elemental sulfur in geologic and environmental samples. Elemental sulfur is first extracted with an organic solvent such as methanol or ethanol by mixing for 3 days and then the extractant is filtered to remove insoluble material. To prepare the sample for concentration and isotopic analysis, an 8-fold excess of DTT was added to a basic solution containing the elemental sulfur extract and the mixture was heated at $50^{\circ} \mathrm{C}$ for 45 minutes under continuous nitrogen gas flow at a rate of 3-5 bubbles per second (Figure 1). Phosphoric acid was then added to evolve hydrogen sulfide gas for 90 minutes under nitrogen gas flow into a sulfide trap of ammonium hydroxide. The multi-welled block heater (36 positions) allowed for the reduction of multiple samples. As tested here, 10 simultaneous reductions were commonly accomplished; however, the apparatus can easily be scaled to use all positions, greatly improving the rate of sample throughput for concentration and sulfur isotope analysis. All components in this analysis have been designed to operate in standard analytical laboratories as well as in field or mobile laboratories. Additionally, these reactions have been designed to extract elemental sulfur in small volumes saving time, resources, and space.

\subsection{Optimal extraction conditions}


The highest recovery of elemental sulfur occurred under basic conditions at pH 11 (Table 1). A solution of sodium citrate with sodium hydroxide was used to maintain the high $\mathrm{pH}$ throughout the reduction process. A basic environment was essential to ensure the thiolate form of DTT was dominant in solution as the $\mathrm{pKa}$ of the thiols are 9.2 and 10.1. At lower $\mathrm{pH}$, reduction was much slower due to the absence of thiolate groups in the reaction matrix (Kwasniewski et al., 2011). The concentration of DTT was also kept at an 8-fold excess relative to the starting elemental sulfur to compensate for the rapid oxidation of the free thiols to inactive disulfides as well as to drive the reaction to completion. The oxidation of thiol groups from DTT does not contaminate the sample because the organic disulfides are retained in the reaction vessel (vacutainer) and are not volatilized to the sulfide trap that contains the extracted sulfur (Figure 1).

Although the reduction step is optimal under alkaline conditions, the volatilization of hydrogen sulfide $(\mathrm{pKa}=7)$ can only occur under more acidic conditions. The addition of phosphoric acid to the reaction vessel after the reduction step ensured that the reduced sulfur was converted to hydrogen sulfide gas and could be bubbled out of the solution. The evolved gas was then collected in a sulfide trap containing an ammonium hydroxide solution. The trap solution was kept at a high $\mathrm{pH}(>9)$ to ensure that the hydrogen sulfide would deprotonate to non-volatile hydrogen bisulfide and remain in solution. The method presented here used a sealed glass vacutainer as the trap with teflon tubing (Figure 1); however, the procedure can be further modified to use an uncapped plastic test tube instead of the vacutainer. Additionally, the teflon 
tubing going into the trap can be replaced with a disposable glass pasteur pipette. Once fully dissolved in the sulfide trap, the sulfide concentrations were immediately measured and then precipitated for sulfur isotopic analysis from the same sample reduction.

Based on short term and long-term changes in absorbance, the optimal DTT reduction reaction time occurs at 45 minutes; less and the reaction is incomplete, more and artifacts are introduced by continued but slower reactions in the vessel (Figure 3). The reduction procedure proceeds with a great excess of DTT to force the reaction to completion (Kwasniewski et al., 2011). Once the elemental sulfur sample has been reduced to bisulfide, there remains an excess of DTT in the mixture that interferes with the spectrophotometric detection method. Initial experiments indicate that the DTT molecule interferes with spectrophotometry by lowering the total absorption upon addition of the colorimetric reagents. Voltammetric analysis of the sample was also complicated by the DTT molecules in the matrix. The thiols on DTT form a complex with the mercury electrode and are stripped off at $-0.8 \mathrm{~V}$, concurrently with the sulfide, making them impossible to distinguish. Additionally, initial experiments revealed that DTT precipitates with silver nitrate (and zinc acetate), which precludes sulfur isotopic analysis of the samples collected in the reaction vacutainer.

From these observations, transferring the bisulfide product from the reductant mixture in the extraction vessel is a critical step in the procedure (Step 2; Figure 1). The addition of phosphoric acid is important for protonating the newly formed bisulfide for transference as hydrogen sulfide 
to the trap and for stopping the DTT reaction, thereby preventing the formation of any byproducts that can interfere with the analysis.

\subsection{DTT reduction specificity and potential uses}

Reducing conditions in modern and ancient lacustrine and marine environments host multiple sulfur species such as elemental sulfur, sulfide, sulfate, and a variety of organic and inorganic sulfur compounds. The specificity of DTT reduction to elemental sulfur makes it valuable in isolating and measuring elemental sulfur as intermediates in microbial reactions. Often the sulfide and sulfate concentration and isotope data only reveal part of the sulfur cycling story and omit the presence of key reaction intermediates (e.g., Leavitt et al., 2013). Likewise, improving the ability to extract elemental sulfur from unconsolidated and lithified sediments would supplement traditional pyrite and sulfate mineral data to better interpret past biogeochemical cycling (e.g. Muller et al., 2017).

Reaction with DTT quantitatively reduces elemental sulfur dissolved in ethanol and methanol to bisulfide, which can then be stripped from solution by acidification and transfer in an anaerobic gas stream to a sulfide trap (>93\% yields; Table 1 ). For the elemental sulfur experiments, there was no observable difference between the instruments used to quantify the amount of sulfide produced during reduction. Sulfide detection by spectrophotometry with the portable Hach instrument, the Epoch microplate reader, and voltammetry produced comparable results. 
Additional controlled reduction experiments revealed that DTT does not reduce sulfate, sulfite, pyrite, or organic sulfur (Table 1). It has been demonstrated that chromium(II) reduces sulfite to sulfide (Kallmeyer et al., 2004). The non-reaction between DTT and sulfite provides an alternative method where measuring sulfite concentrations may be critical to culturing experiments (e.g., Habicht et al., 1998) or environments that contain sulfur intermediates in addition to elemental sulfur (e.g., Zopfi et al., 2004). Although DTT potentially reduces wetted elemental sulfur (45.4\% recovery) and thiosulfate (24.9\% recovery; Table 1$)$, the partial recovery of these species should not skew measurements of the elemental sulfur fraction if only the dissolved inorganic fraction is analyzed. In the natural samples analyzed here, only sulfur that was soluble in organic solvents as $\alpha-S_{8}$ molecules was recovered and fully reduced by DTT.

Extraction and quantification of elemental sulfur from Weimarn sols (hydrophobic) and Raffo sols (hydrophilic) were investigated in this study because of their similarity to sulfur globules excreted by sulfur oxidizing bacteria (Steudel, 2003). In both cases, DTT reduction of the sols resulted in poor recovery $(<10 \%$; Table 1$)$. This may be due to the DTT molecules encountering steric repulsion and a limited contact area on the nanoparticles for reduction to occur. This effect may also explain the partial recovery of wetted elemental sulfur given that a full recovery of dissolved elemental sulfur was confirmed.

The partial recovery of sulfur from thiosulfate molecules (24.9\%; Table 1) may be explained from the formation of Raffo sols. These sols are prepared by adding sodium thiosulfate to 
concentrated acid which form aggregated hydrophilic sulfur globules in the presence of potassium chloride as described by Steudel (2003). In the DTT reduction procedure, the addition of phosphoric acid to thiosulfate formed $\alpha-\mathrm{S}_{8}$ (confirmed using X-ray diffraction). This acidification step can also produce sulfur dioxide from the initial thiosulfate (Steudel, 2003). The newly formed $\alpha-S_{8}$ is then the primary sulfur species that is reduced. The partial recovery is due to the $\mathrm{pH}$ of the reaction mixture being lowered by the acidification and decreasing the effectiveness of the reduction by DTT (Kwasniewski et al., 2011).

The complete recovery of tetrasulfide during DTT reduction (Table 1) has not to our knowledge been previously reported. Although acidification of tetrasulfide is known to produce both elemental sulfur as Raffo sol and hydrogen sulfide gas below pH 10 (Kamyshny et al., 2004), full recovery observed here indicates that DTT reacts directly with and reduces tetrasulfide before the acidification step. DTT reduction of tetrasulfide can potentially be used to selectively isolate and quantify polysulfides in aqueous and solid phase samples.

The lake sediments were studied as proof of concept for this new method (Figure 4). The concentration data indicated a large amount of elemental sulfur present in the first $5 \mathrm{~cm}$ of the lake sediment ( 252 to $900 \mathrm{ug} / \mathrm{g}$ ) and then a large decrease with depth as the conditions became more reducing. The presence of elemental sulfur within the recent sediments is typical of many freshwater lakes and coastal marine settings (Berner, 1970; Howarth, 1984; Ferdelman et al., 1991; Thamdrup et al, 1993; Holmer \& Storkholm, 2001). 


\subsection{Sulfur Isotopes}

The $\delta^{34} \mathrm{~S}$ values of sulfur compounds extracted from water columns and sediments are often used to reconstruct the redox environment and the pathways of diverse microbial sulfur cycling within lacustrine and marine environments (e.g., Antler et al., 2013; Gilhooly et al., 2016; Mills et al., 2016). Sulfate reducing bacteria are well known to produce large sulfur isotope fractionations (Rees, 1973; Brunner et al., 2005; Sim et al., 2011; Leavitt et al., 2013). The hydrogen sulfide produced during microbial sulfate reduction is rapidly oxidized to elemental sulfur, polysulfides, and thiosulfate (Canfield et al., 2010; Hansel et al., 2015). Elemental sulfur formed from abiotic and biotic oxidation of sulfide retains the isotopic composition of the sulfide reactant (Fry et al., 1988; Canfield, 1994; Zerkle et al., 2009; Brabec et al., 2012); however, subsequent cycles of sulfide oxidation and disproportionation reactions produce ${ }^{34} \mathrm{~S}$-depleted elemental sulfur and sulfide (Canfield, 1994; Thamdrup et al., 1994b; Böttcher, et al., 2001). Such rapid (cryptic) cycling of sulfur intermediates is difficult to study. DTT reduction presented here could be a significant improvement to investigations of lacustrine and marine environments provided the primary sulfur isotope composition remains unaltered during sample collection and extraction.

Controlled experiments conducted herein demonstrate that DTT reduction does not fractionate the sulfur isotope composition of elemental sulfur. The reactant elemental sulfur and product sulfide had statistically identical $\delta^{34} \mathrm{~S}$ values in the range of 19.2 to $20.6 \%$ (Figure 5). The 
isotope data also indicate that DTT addition does not contaminate the sample. The DTT molecule contains two thiol groups which potentially can be exchanged during sulfur reduction. The bulk $\delta^{34} \mathrm{~S}$ of DTT $(-8.1 \%$ o \pm 0.1$)$ is significantly lower than the $\delta^{34} \mathrm{~S}$ of the elemental sulfur. No analytical difference was observed between the isotopic composition of stock elemental sulfur solutions (either in ethanol or water) and the sulfide produced during DTT reduction, which suggests there is no obvious mixing between DTT thiols and the sulfur from the sample.

The large sulfur isotopic difference between DTT thiols and sample sulfide provide evidence for the reaction (Figure 6) proposed by Kwasniewski et al. (2011). In this mechanism, the sulfur atoms from the elemental sulfur molecule are reduced to hydrogen sulfide (which deprotonates at $\mathrm{pH}$ 11) while the DTT thiols are oxidized to a disulfide bond. The identical $\delta^{34} \mathrm{~S}$ values of the produced sulfide relative to the starting elemental sulfur are isotopically distinct from the DTT thiols, which indicates that all the sulfur atoms in the hydrogen sulfide produced during reduction are in fact originating from the elemental sulfur ring and that the reaction goes to completion.

Although quantitative for elemental sulfur, tetrasulfide and thiosulfate also reacted with DTT (Table 1). Tetrasulfide was reacted as a proxy for polysulfides commonly observed in reducing environments (e.g. Kamyshny et al., 2004). DTT reduction of tetrasulfide is quantitative (100\% recovery, Table 1); however, an average fractionation of $4.4 \%=0.2$ was observed between the starting material and the reduced product (Figure 5). Sulfur isotope fractionation during DTT 
reduction of tetrasulfide suggests that the reduction mechanism for polysulfide species is distinctly different from elemental sulfur (as proposed in Figure 6). Despite the consistent fractionation during DTT reduction of tetrasulfide, sample collection of polysulfides in anoxic water columns, pore waters and the laboratory setting is highly problematic. Polysulfides rapidly disproportionate and oxidize and will likely be altered during sample preparation. A simple experiment conducted for evaluating this method, demonstrated that the tetrasulfide dissolved in either ethanol or methanol rapidly oxidized in the presence of dissolved molecular oxygen; however, the oxidation product was not easily identified. X-ray diffraction analysis did not correspond to $\alpha-S_{8}$ or any other elemental sulfur polymorph in the crystallographic open database. Furthermore, polysulfides in an aqueous mixture with sulfide and elemental sulfur form a rapid equilibrium through sulfur isotope exchange (Kamyshny et al., 2003; Rickard \& Luther, 2007).

The reduction experiments also indicated that thiosulfate is reducible during the extraction procedure. Sulfur is cleaved from thiosulfate during the acidification step of the method (Steudel, 2003), producing elemental sulfur depleted in ${ }^{34} \mathrm{~S}$ by an average of $10.3 \%$ \pm 0.5 relative to the starting thiosulfate. This fractionation likely indicates that other byproducts, such as sulfur dioxide, are enriched in ${ }^{34} \mathrm{~S}$ relative to the elemental sulfur. By studying the fractionation of thiosulfate during the formation of Raffo sols, new insight into microbial mechanisms that produce intracellular sulfur globules can be discovered. These hydrophilic sulfur globules have been known to even dissolve small sulfur homocycles, such as $\mathbf{S}_{8}$, (Steudel, 2003) allowing 
microorganisms to transport elemental sulfur.

\section{Conclusions}

DTT reduction improves upon traditional methods with, quantitative and selective reduction of elemental sulfur from both laboratory and natural samples. Simultaneous measurements of concentration and sulfur isotope composition of DTT reducible sulfur (DRS) is analytically robust and provides a new tool for studying the sulfur intermediates associated with microbial metabolism as well as cryptic sulfur cycling. Compared to chromium reduction, DTT reduction has distinct advantages because the procedure does not require boiling, specialty glassware is not needed, and the apparatus enables a far greater number of concurrent sample analyses. The compact design is highly portable that, when combined with a portable spectrophotometer, can easily be used in the field such as at an outcrop or on a research vessel. Sulfur isotope analysis indicated that elemental sulfur is completely reduced, with no apparent fractionation between the reactant elemental sulfur and the DTT-reduced sulfide product. The comparison of elemental sulfur $\delta^{34} \mathrm{~S}$ relative to the $\delta^{34} \mathrm{~S}$ of DTT thiols indicated no contamination of the sample during reduction. This method has been optimized for sediment and rock samples. With proper sample extraction and solvent pretreatment, DTT reduction is readily applicable to both water column and pore water samples.

Additional outcomes of the tests conducted herein indicated that polysulfide in the form of 
sodium tetrasulfide is quantitatively reduced by DTT. Tetrasulfide reduction resulted in a fractionation of $4.4 \% \pm 0.2$, indicating a reaction mechanism that differs from that of elemental sulfur. Thiosulfate along with colloidal sulfur in the form of Weimarn and Raffo sols were partially reduced $(24.9 \%$ and $<10 \%$ recovery, respectively) using DTT reduction.

\section{Acknowledgements}

We thank Jacob Burch (IUPUI) and Alyssa Henke (IUPUI) for their assistance with elemental sulfur and pyrite extractions. We would like to acknowledge the Integrated Nanosystems Development Institute (INDI) at IUPUI for use of their Bruker D8 Discover X-Ray Diffraction Instrument, which was awarded through a National Science Foundation grant [MRI-1429241]. We appreciate those who provided samples for our experiments: Brenda Blacklock (IUPUI) provided cysteine, William Elliott (University of Southern Indiana) provided shale, Amy Myrbo (LacCore and Continental Scientific Drilling Coordination Office, University of Minnesota) provided lake sediment, and Philippe Schmitt-Kopplin (Helmholtz Zentrum München) provided dissolved organic matter. The manuscript benefited from helpful suggestions made by Alice Bosco-Santos (UNICAMP; IUPUI). We thank Editor-in-Chief Michael Böttcher and two anonymous reviewers for their thoughtful and helpful comments. This work was supported by a National Science Foundation grant [EAR-1424228] to WPG and JPW. 


\section{References}

Alberta Environment and Parks, 2015. Development and validation of analytical methods for elemental Sulphur in Alberta Soils, Prepared by Maxxam Analytics International Corporation for Alberta Environment and Parks, June 2015, Edmonton, Alberta.

Antler, G., Turchyn A. V., Rennie, V., Herut, B. and Sivan, O. (2013) Coupled sulfur and oxygen isotope insight into bacterial sulfate reduction in the natural environment. Geochimica et Cosmochimica Acta, 118, 98-117.

Berner, R. A. (1970). Sedimentary pyrite formation. American journal of science, 268(1), 1-23.

Böttcher, M. E., Thamdrup, B., \& Vennemann, T. W. (2001). Oxygen and sulfur isotope fractionation during anaerobic bacterial disproportionation of elemental sulfur. Geochimica et Cosmochimica Acta, 65(10), 1601-1609.

Brunner, B., \& Bernasconi, S. M. (2005). A revised isotope fractionation model for dissimilatory sulfate reduction in sulfate reducing bacteria. Geochimica et Cosmochimica Acta, 69(20), 47594771.

Brabec, M.Y., Lyons, T.W., \& Mandernack, K.W. (2012). Oxygen and sulfur isotope fractionation during sulfide oxidation by anoxygenic phototrophic bacteria Geochimica Cosmochimica Acta, 83, 234-251.

Burton, E. D., Sullivan, L. A., Bush, R. T., Johnston, S. G., \& Keene, A. F. (2008). A simple and inexpensive chromium-reducible sulfur method for acid-sulfate soils. Applied Geochemistry, 23(9), 2759-2766.

Canfield, D. E., Raiswell, R., Westrich, J. T., Reaves, C. M., \& Berner, R. A. (1986). The use of 
chromium reduction in the analysis of reduced inorganic sulfur in sediments and shales. Chemical geology, 54(1-2), 149-155.

Canfield, D. E., \& Thamdrup, B. (1994). The production of ${ }^{34}$ S-depleted sulfide during bacterial disproportionation of elemental sulfur. Science, 266(5193), 1973.

Canfield, D. E., Stewart, F. J., Thamdrup, B., De Brabandere, L., Dalsgaard, T., Delong, E. F., Revsbech, N. P., \& Ulloa, O. (2010). A cryptic sulfur cycle in oxygen-minimum-zone waters off the Chilean coast. Science, 330(6009), 1375-1378.

Cleland, W. W. (1964). Dithiothreitol, a new protective reagent for SH groups. Biochemistry, $3(4), 480-482$.

Coplen, T. B., Kendall, C., \& Hopple, J. (1983). Comparison of stable isotope reference samples. Nature, 302(5905), 236-238.

Dahl, C., \& Prange, A. (2006). Bacterial sulfur globules: occurrence, structure and metabolism. In Inclusions in prokaryotes (pp. 21-51). Springer Berlin Heidelberg.

Ferdelman, T. G., Church, T. M., \& Luther, G. W. (1991). Sulfur enrichment of humic substances in a Delaware salt marsh sediment core. Geochimica et Cosmochimica Acta, 55(4), 979-988.

Fossing, H., \& Jørgensen, B. B. (1989). Measurement of bacterial sulfate reduction in sediments: evaluation of a single-step chromium reduction method. Biogeochemistry, 8(3), 205-222.

Fry, B., Ruf, W., Gest, H., \& Hayes, J.M. (1988). Sulfur isotope effects associated with oxidation of sulfide by $\mathrm{O} 2$ in aqueous solution. Chemical Geology, 73(3), 205-210.

Garcia, A. A., \& Druschel, G. K. (2014). Elemental sulfur coarsening kinetics. Geochemical 
transactions, 15(1), 11.

George, G. N., Gnida, M., Bazylinski, D. A., Prince, R. C., \& Pickering, I. J. (2008). X-ray absorption spectroscopy as a probe of microbial sulfur biochemistry: the nature of bacterial sulfur globules revisited. Journal of bacteriology, 190(19), 6376-6383.

Gilhooly, W. P., III, Reinhard, C. T., \& Lyons, T. W. (2016). A comprehensive sulfur and oxygen isotope study of sulfur cycling in a shallow, hyper-euxinic meromictic lake. Geochimica et Cosmochimica Acta, 189, 1-23.

Habicht, K.S., Canfield, D.E. and Rethmeier, J., 1998. Sulfur isotope fractionation during bacterial reduction and disproportionation of thiosulfate and sulfite. Geochimica et Cosmochimica Acta, 62, 2585-2595.

Hansel, C. M., Ferdelman, T. G., \& Tebo, B. M. (2015). Cryptic cross-linkages among biogeochemical cycles: novel insights from reactive intermediates. Elements, 11(6), 409-414. Hardman, A. F., \& Barbehenn, H. E. (1935). Determination of free sulfur in rubber. Industrial \& Engineering Chemistry Analytical Edition, 7(2), 103-104.

Holmer, M., \& Storkholm, P. (2001). Sulphate reduction and sulphur cycling in lake sediments: a review. Freshwater Biology, 46(4), 431-451.

Howarth, R. W. (1984). The ecological significance of sulfur in the energy dynamics of salt marsh and coastal marine sediments. Biogeochemistry, 1(1), 5-27.

Johnston, D.T., Gill, B.C., Masterson, A., Beirne, E., Casciotti, K.L., Knapp, A.N. and Berelson, W. (2014). Placing an upper limit on cryptic marine sulphur cycling. Nature, 513, 530-533. Jørgensen, B. B. (1982). Mineralization of organic matter in the sea bed-the role of sulphate 
reduction. Nature, 296(5858), 643-645.

Kallmeyer, J., Ferdelman, T. G., Weber, A., Fossing, H., Jørgensen, B. B. (2004). A cold chromium distillation procedure for radiolabeled sulfide applied to sulfate reduction measurements. Limnology and Oceanography: Methods, 2, 171-180.

Kamyshny, A., Goifman, A., Rizkov, D., \& Lev, O. (2003). Kinetics of disproportionation of inorganic polysulfides in undersaturated aqueous solutions at environmentally relevant conditions. Aquatic Geochemistry, 9(4), 291-304.

Kamyshny, A., Goifman, A., Gun, J., Rizkov, D., \& Lev, O. (2004). Equilibrium distribution of polysulfide ions in aqueous solutions at $25 \mathrm{C}$ : a new approach for the study of polysulfides' equilibria. Environmental science \& technology, 38(24), 6633-6644.

Kamyshny Jr, A. (2009). Improved cyanolysis protocol for detection of zero-valent sulfur in natural aquatic systems. Limnology and Oceanography: Methods, 7, 442-448.

Kleinjan, W. E., de Keizer, A., \& Janssen, A. J. (2003). Biologically produced sulfur. Elemental sulfur and sulfur-rich compounds I, 44-57.

Kleinjan, W. E. (2005). Biologically produced sulfur particles and polysulfide ions.

Kwasniewski, M. T., Allison, R. B., Wilcox, W. F., \& Sacks, G. L. (2011). Convenient, inexpensive quantification of elemental sulfur by simultaneous in situ reduction and colorimetric detection. Analytica chimica acta, 703(1), 52-57.

Leavitt, W. D., Halevy, I., Bradley, A. S., \& Johnston, D. T. (2013). Influence of sulfate reduction rates on the Phanerozoic sulfur isotope record. Proceedings of the National Academy of Sciences, 110(28), 11244-11249. 
Luther, G. W., Glazer, B. T., Ma, S., Trouwborst, R. E., Moore, T. S., Metzger, E., Kraiya, C. \& Taillefert, M. (2008). Use of voltammetric solid-state (micro) electrodes for studying biogeochemical processes: laboratory measurements to real time measurements with an in situ electrochemical analyzer (ISEA). Marine Chemistry, 108(3), 221-235.

Mayer, S. A., \& Myrbo, A. (2013). Reconstructing past sulfur loading in Little Sandy Lake, a wild rice lake in northern Minnesota. Geological Society of America Abstracts with Programs, $44(7), 378$.

Mills, J. V., Antler, G., \& Turchyn, A. V. (2016). Geochemical evidence for cryptic sulfur cycling in salt marsh sediments. Earth and Planetary Science Letters, 453, 23-32.

Muller, É., Ader, M., Chaduteau, C., Cartigny, P., Baton, F., \& Philippot, P. (2017). The use of chromium reduction in the analysis of organic carbon and inorganic sulfur isotope compositions in Archean rocks. Chemical Geology, 457, 68-74.

Newton, R. J., Bottrell, S. H., Dean, S. P., Hatfield, D., \& Raiswell, R. (1995). An evaluation of the use of the chromous chloride reduction method for isotopic analyses of pyrite in rocks and sediment. Chemical Geology, 125(3-4), 317-320.

Perdue, E. M. (2013). Standard and reference samples of humic acids, fulvic acids, and natural organic matter from the Suwannee River, Georgia: thirty years of isolation and characterization. In Functions of Natural Organic Matter in Changing Environment (pp. 85-88). Springer, Dordrecht.

Picard, A., Gartman, A., \& Girguis, P. R. (2016). What Do We Really Know about the Role of Microorganisms in Iron Sulfide Mineral Formation?. Frontiers in Earth Science, 4, 68. 
Rees, C. E. (1973). A steady-state model for sulphur isotope fractionation in bacterial reduction processes. Geochimica et Cosmochimica Acta, 37(5), 1141-1162.

Rickard, D., \& Luther G. W. (2007) Chemistry of Iron Sulfides. Chemical Reviews, 107(2), 514562.

Rickard, D., Mussmann, M. and Steadman, J.A. (2017). Sedimentary sulfides. Elements, 13(2), 117-122.

Sim, M. S., Bosak, T., \& Ono, S. (2011). Large sulfur isotope fractionation does not require disproportionation. Science, 333(6038), 74-77.

Steudel, R., \& Holdt, G. (1988). Solubilization of elemental sulfur in water by cationic and anionic surfactants. Angewandte Chemie International Edition in English, 27(10), 1358-1359. Steudel, R. (1989). On the nature of the "elemental sulfur"(S0) produced by sulfur-oxidizing bacteria—a model for S0 globules. Autotrophic bacteria, 289-303.

Steudel, R. (1996). Mechanism for the formation of elemental sulfur from aqueous sulfide in chemical and microbiological desulfurization processes. Industrial \& engineering chemistry research, 35(4), 1417-1423.

Steudel, R., \& Eckert, B. (2003). Solid sulfur allotropes sulfur allotropes. In Elemental sulfur and sulfur-rich compounds I (pp. 1-80). Springer Berlin Heidelberg.

Steudel, R. (2003). Aqueous sulfur sols. In Elemental Sulfur and Sulfur-Rich Compounds I (pp. 153-166). Springer Berlin Heidelberg.

Steudel, R. (2015). Solubility of elemental sulfur (orthorhombic alpha-S8) in organic solvents at 25C. DOI: 10.13140/RG.2.1.2903.1769. 
Stevens, R., Stevens, L., \& Price, N. C. (1983). The stabilities of various thiol compounds used in protein purifications. Biochemistry and Molecular Biology Education, 11(2), 70-70.

Thamdrup, B. O., Finster, K., Hansen, J. W., \& Bak, F. (1993). Bacterial disproportionation of elemental sulfur coupled to chemical reduction of iron or manganese. Applied and environmental microbiology, 59(1), 101-108.

Thamdrup, B., Fossing, H., \& Jørgensen, B. B. (1994a). Manganese, iron and sulfur cycling in a coastal marine sediment, Aarhus Bay, Denmark. Geochimica et Cosmochimica Acta, 58(23), $5115-5129$.

Thamdrup, B., Finster, K., Fossing, H., Hansen, J. W., \& Jørgensen, B. B. (1994b). Thiosulfate and sulfite distributions in porewater of marine sediments related to manganese, iron, and sulfur geochemistry. Geochimica et Cosmochimica Acta, 58(1), 67-73.

Zerkle, A. L., Farquhar, J., Johnston, D. T., Cox, R. P., \& Canfield, D. E. (2009). Fractionation of multiple sulfur isotopes during phototrophic oxidation of sulfide and elemental sulfur by a green sulfur bacterium. Geochimica et Cosmochimica Acta, 73(2), 291-306.

Zopfi, J., Ferdelman, T. G., \& Fossing, H. (2004). Distribution and fate of sulfur intermediatessulfite, tetrathionate, thiosulfate, and elemental sulfur - in marine sediments. Geological Society of America Special Papers, 379, 97-116. 
Figure Captions

Figure 1. Schematic of the DTT reduction procedure and apparatus. A) The sample extract is reduced with DTT in a basic solution $(\mathrm{pH}=11)$ for 45 minutes to reduce elemental sulfur to nonvolatile bisulfide ions $\left(\mathrm{HS}^{-}\right)$. B) In the same vacutainer, the extractant is acidified with concentrated phosphoric acid at $50^{\circ} \mathrm{C}$ for 90 minutes to protonate the $\mathrm{HS}^{-}$ion to $\mathrm{H}_{2} \mathrm{~S}$ gas.

Nitrogen carrier gas creates anaerobic conditions in both the base and acid step, and transfers $\mathrm{H}_{2} \mathrm{~S}$ from the reduction vessel to the base trap where it is deprotonated to non-volatile $\mathrm{HS}^{-}$.

Chemical reactions are depicted by dashed arrows and gas flow is represented by solid arrows.

Figure 2. Optimal pH for DTT reduction.

Figure 3. Sulfide absorbance as a function of reaction time.

Figure 4. Depth profile of average elemental sulfur concentrations $(n=3)$ in lake sediment. Error bars represent $1 \sigma$ standard deviation from the mean.

Figure 5. Average $\delta^{34} \mathrm{~S}(\mathrm{n}=3)$ of DTT reagent (gray shaded area), stock DTT-reducible sulfur compounds (filled symbols) and the reduction products (open symbols). Vertical shaded area indicates the isotopic range of unreacted elemental sulfur.

Figure 6. Simplified molecular reaction scheme between DTT and elemental sulfur $\left(\alpha-\mathrm{S}_{8}\right)$ producing hydrogen sulfide, as proposed by Kwasniewski et. al. (2011). 
Table 1. Sulfur recoveries in pure chemicals and natural samples with DTT reduction

\begin{tabular}{|c|c|c|c|}
\hline Substance & Concentration & Recovery & $\mathbf{n}$ \\
\hline \multicolumn{4}{|l|}{ Elemental sulfur } \\
\hline Elemental sulfur in methanol $^{\mathrm{A}}$ & $57.5 \mu \mathrm{M}$ & $99.2 \% \pm 5.4$ & 3 \\
\hline Elemental sulfur in methanol $^{\mathrm{B}}$ & $46.0 \mu \mathrm{M}$ & $102 \% \pm 0.4$ & 3 \\
\hline Elemental sulfur in methanol ${ }^{\mathrm{C}}$ & $62.5 \mu \mathrm{M}$ & $94.5 \% \pm 4.2$ & 3 \\
\hline Elemental sulfur in ethanol $^{\mathrm{A}}$ & $62.3 \mu \mathrm{M}$ & $93.4 \% \pm 4.2$ & 3 \\
\hline Elemental sulfur in ethanol ${ }^{\mathrm{B}}$ & $62.3 \mu \mathrm{M}$ & $105 \% \pm 1.0$ & 3 \\
\hline Elemental sulfur in ethanol ${ }^{\mathrm{C}}$ & $62.3 \mu \mathrm{M}$ & $97.0 \% \pm 3.4$ & 3 \\
\hline Elemental sulfur in water ${ }^{\mathrm{A}}$ & 26 to $90 \mu \mathrm{M}$ & $45.4 \% \pm 14.4$ & 5 \\
\hline \multicolumn{4}{|c|}{ Colloidal elemental sulfur and polysulfide } \\
\hline Sulfur from Weimarn sol ${ }^{\mathrm{A}}$ & $62.5 \mu \mathrm{M}$ & $<10.0 \%$ & 6 \\
\hline Sulfur from Raffo sol ${ }^{\mathrm{A}}$ & $125 \mu \mathrm{M}$ & $<10.0 \%$ & 3 \\
\hline Sodium tetrasulfide $\left(\mathrm{Na}_{2} \mathrm{~S}_{4}\right)^{\mathrm{A}}$ & $143 \mu \mathrm{M}$ & $100 \% \pm 2.3$ & 3 \\
\hline \multicolumn{4}{|l|}{ Sulfate, Sulfite and Thiosulfate } \\
\hline Sodium sulfate $\left(\mathrm{Na}_{2} \mathrm{SO}_{4}\right)^{\mathrm{A}}$ & $25,50,75,100 \mu \mathrm{M} ; 1,100,500 \mathrm{mM}$ & NR & 3 \\
\hline Sodium sulfite $\left(\mathrm{Na}_{2} \mathrm{SO}_{3}\right)^{\mathrm{B}}$ & $100 \mu \mathrm{M}$ & NR & 3 \\
\hline Sodium thiosulfate $\left(\mathrm{Na}_{2} \mathrm{~S}_{2} \mathrm{O}_{3}\right)^{\mathrm{A}}$ & $63.4 \mu \mathrm{M}$ & $24.9 \% \pm 6.2$ & 3 \\
\hline
\end{tabular}


Pyrite $\left(\mathrm{FeS}_{2}\right)^{\mathrm{A}}$

$200 \mu \mathrm{M}$

NR

3

Pennsylvanian pyritic shale ${ }^{\mathrm{A}}$

$1830 \mu \mathrm{g} / \mathrm{g}$

NR

6

Organic sulfur

L-Cysteine $^{\mathrm{A}}$

$152 \mu \mathrm{M}$

NR

3

Suwannee River organic matter ${ }^{\mathrm{A}}$

$0.831 \mathrm{mg} / \mathrm{mL}$

NR

3

Pennsylvanian pyritic shale ${ }^{\mathrm{A}}$

$118 \mu \mathrm{g} / \mathrm{g}$

NR

A: Quantified using portable Hach absorption spectrophotometer

B: Quantified using cyclic voltammetry

C: Quantified using benchtop Epoch microplate reader

NR: No recovery 




Figure 1 


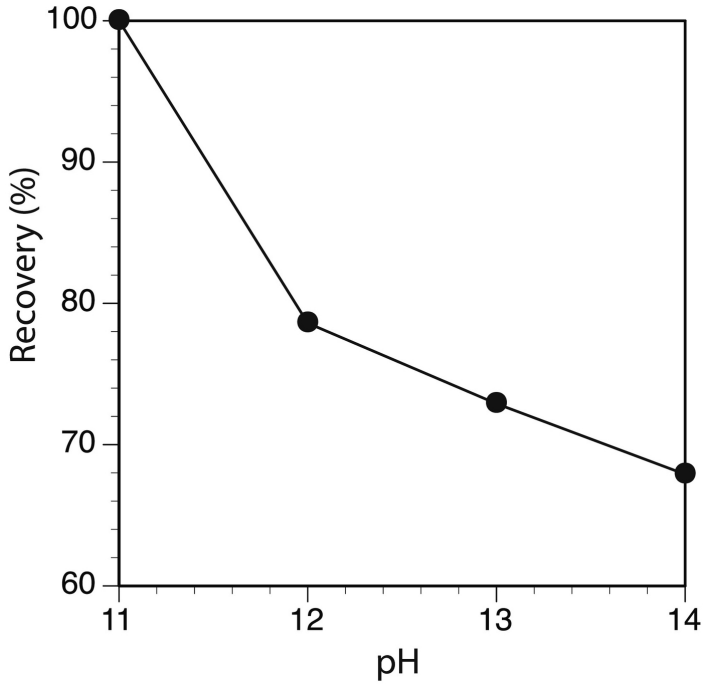

Figure 2 


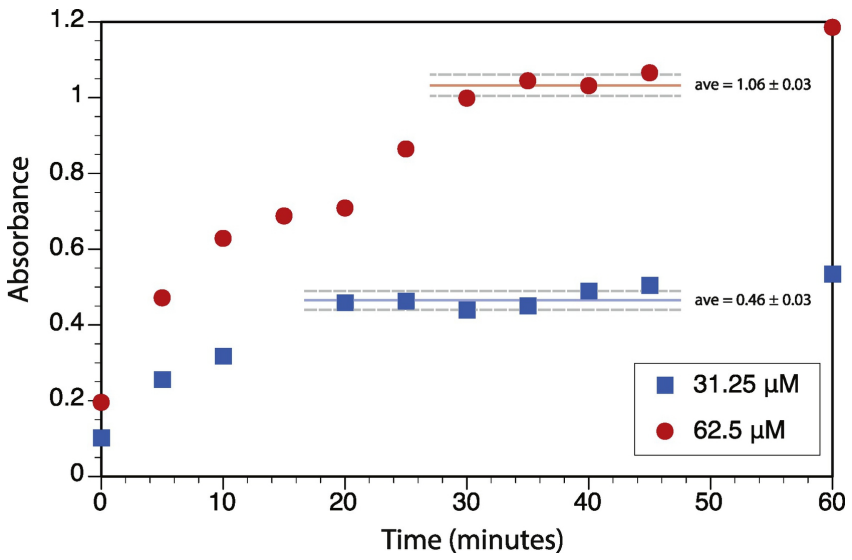

Figure 3 
Elemental Sulfur (ppm)

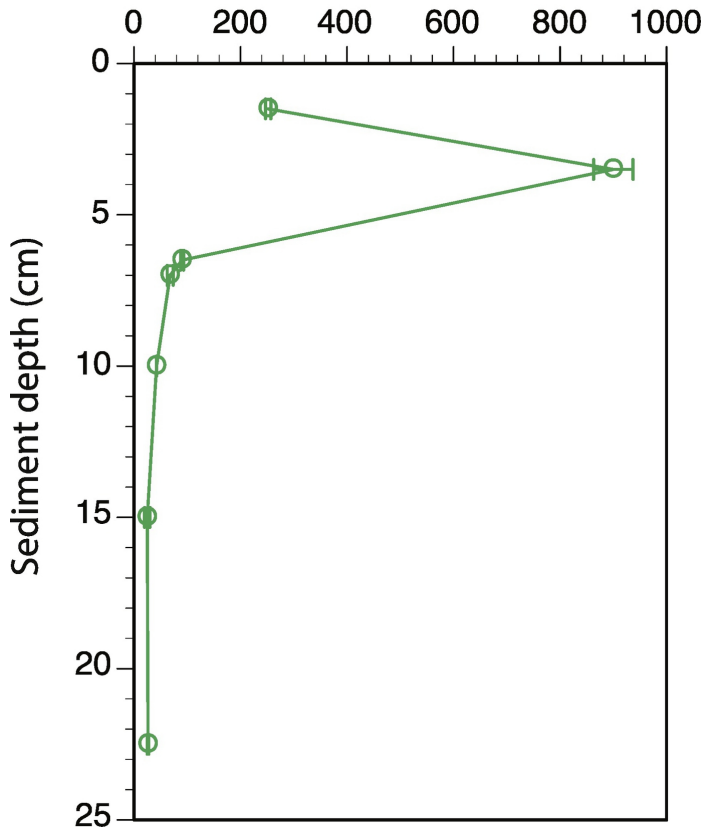

Figure 4 


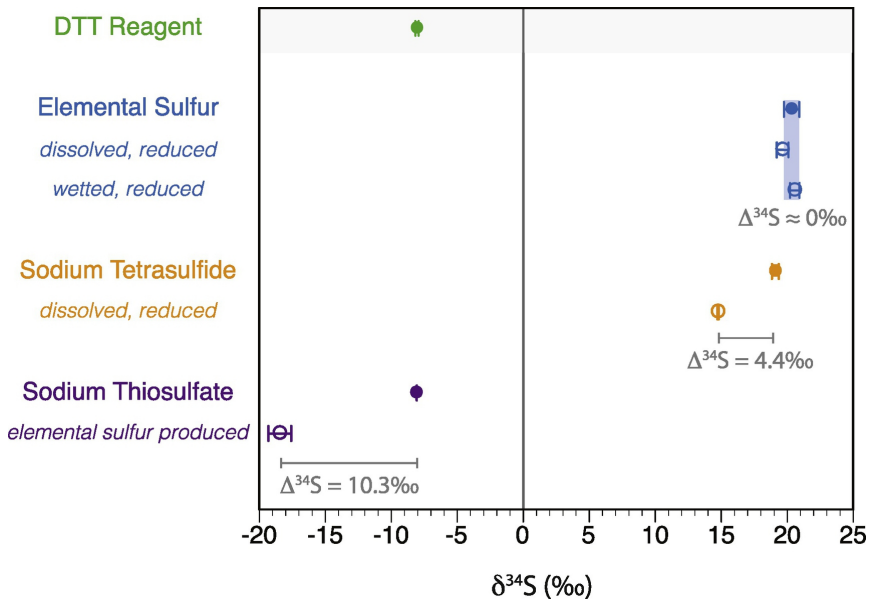

Figure 5 

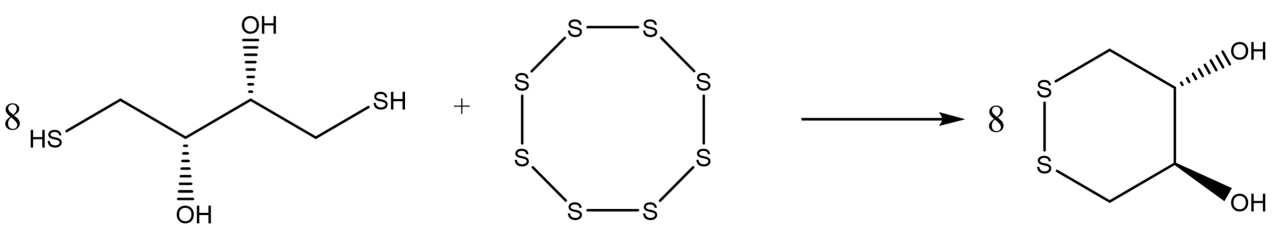

Figure 6 